\title{
Control of GABA release at mossy fiber-CA3 connections in the developing hippocampus
}

\section{Victoria F. Safiulina', Maddalena D. Caiati', Sudhir Sivakumaran', Giacomo Bisson', Michele Migliore ${ }^{2}$ and Enrico Cherubini ${ }^{1 *}$}

\author{
Department of Neurobiology, International School for Advanced Studies, Trieste, Italy \\ 2 Institute of Biophysics, National Research Council, Palermo, Italy
}

Edited by:

Laszlo Acsady, Institute of

Experimental Medicine, Hungary

Reviewed by:

Katalin Toth, Centre de recherche

Universite Laval Robert-Giffard, Canada

Rafael Gutierrez, Centro de

Investigacion y Estudios Avanzados del

IPN, Mexico

*Correspondence:

Enrico Cherubini, Neurobiology Sector, International School of Advanced

Studies, Ed. Q1 Area Science Park,

S.S. 14 Km 163.5, 34012 Basovizza,

Trieste, Italy.

e-mail: cher@sissa.it
In this review some of the recent work carried out in our laboratory concerning the functional role of GABAergic signalling at immature mossy fibres (MF)-CA3 principal cell synapses has been highlighted. While in adulthood MF, the axons of dentate gyrus granule cells release onto CA3 principal cells and interneurons glutamate, early in postnatal life they release GABA, which exerts into targeted cells a depolarizing and excitatory action. We found that GABA mediated postsynaptic currents (MF-GPSCs) exhibited a very low probability of release, were sensitive to L-AP4, a group III metabotropic glutamate receptor agonist, and revealed short-term frequency-dependent facilitation. Moreover, MF-GPSCs were down regulated by presynaptic $\mathrm{GABA}_{\mathrm{B}}$ and kainate receptors, activated by spillover of GABA from MF terminals and by glutamate present in the extracellular medium, respectively. Activation of these receptors contributed to the low release probability and in some cases to synapses silencing. By pairing calcium transients, associated with network-driven giant depolarizing potentials or GDPs (a hallmark of developmental networks thought to represent a primordial form of synchrony between neurons), generated by the synergistic action of glutamate and GABA with MF activation increased the probability of GABA release and caused the conversion of silent synapses into conductive ones suggesting that GDPs act as coincident detector signals for enhancing synaptic efficacy. Finally, to compare the relative strength of CA3 pyramidal cell output in relation to their MF glutamatergic or GABAergic inputs in adulthood or in postnatal development, respectively, a realistic model was constructed taking into account different biophysical properties of these synapses.

Keywords: developing hippocampus, mossy fibres, $\mathrm{GABA}_{A}$-mediated post synaptic currents, presynaptic $\mathrm{GABA}_{B}$ receptors, presynaptic GluK1 receptors, activity-dependent plasticity, realistic modelling, quantal analysis

\section{GABAergic PHENOTYPE OF HIPPOCAMPAL GRANULE CELLS}

The axons of granule cells in the dentate gyrus, the mossy fibres (MFs) are part of the classical glutamatergic trisynaptic circuit in the hippocampus. They provide most of excitatory inputs to CA3 principal cells and GABAergic interneurons present in the hilus and in stratum lucidum (Frotscher et al., 2006). Other inputs to CA3 principal cells include fibres from the enthorinal cortex and from other CA3 pyramidal cells via recurrent collaterals. MFs were called "mossy" by Ramon y Cajal (Ramon y Cajal, 1911) because of their particular shape which is reminiscent of that of the moss on a tree. Thus, in adulthood they form large (3-5 $\mu \mathrm{m}$ diameter) en passant swellings and terminal expansions on CA3 principal neurons or hilar mossy cells, seen as giant boutons at the electron microscopic level. The presynaptic swellings adapt very well to specialized postsynaptic elements present on proximal dendrites of CA3 principal cells, called thorny excrescences. The MF synaptic complex contains multiple active zones (up to 50) associated with postsynaptic densities. Unlikely principal cells, GABAergic interneurons in stratum lucidum, which constitute the large majority of postsynaptic MF targets, are innervated by small en passant boutons or filopodial extensions comprising only one or few release sites (Acsády et al.,
1998). The small number of release sites and the relatively high release probability endows these synapses with distinct functional properties as compared to MF-CA3 synapses (Nicoll and Schmitz, 2005; Bischofberger et al., 2006; McBain, 2008).

Interestingly, at principal cell synapses, giant boutons develop gradually during the first weeks of postnatal life. Light and electron microscopic studies have shown that immediately after birth immature axons terminate in very small spherical expansions which establish both symmetric and asymmetric contacts with proximal dendrites of pyramidal cells (Stirling and Bliss, 1978; Amaral and Dent, 1981). During this period, pyramidal cell dendrites show a marked lateral growth and fingers which began indenting into MF expansions. Moreover, at this developmental stage, the main neurotransmitter released from MF terminals is GABA which exerts into targeted cells a depolarizing and excitatory action (Safiulina et al., 2006; Sivakumaran et al., 2009).

In this paper we will review recent findings obtained in our laboratory on immature MF-CA3 connections highlighting also new data on GABAergic signalling at these synapses. In particular, we will discuss these results in view of their possible implications in network excitability and information processing. 


\section{EARLY IN POSTNATAL LIFE THE MAIN NEUROTRANSMITTER RELEASED FROM MOSSY FIBRE (MF) TERMINALS IS GABA}

The presence of GABA in stratum lucidum was initially described by Ottersen and Storm-Mathisen (1984) who concluded that this neurotransmitter is stored in MF terminals together with glutamate. In addition, evidence has been provided that MFs express GAD65 and GAD67 (Schwarzer and Sperk, 1995; Sloviter et al., 1996) as well as the mRNA for the vesicular GABA transporter, VGAT (Lamas et al., 2001; Gómez-Lira et al., 2005). Moreover, hippocampal pyramidal neurons are able to express, in addition to glutamate, "mistargeted" $\mathrm{GABA}_{\mathrm{A}}$ receptors which, in particular conditions may become functional (Rao et al., 2000). This suggests that MFs can use GABA as a neurotransmitter since they posses all the machinery for synthesising, storing, releasing and sensing it. Indeed, in juvenile animals, it has been shown that stimulation of MFs elicits in CA3 pyramidal neurons AMPA and GABA -mediated synaptic currents (Walker et al., 2001; Gutierrez et al., 2003). In addition, immunogold experiments have demonstrated that AMPA and $\mathrm{GABA}_{\mathrm{A}}$ receptors are co-localized on the same synapse in close apposition to MF terminals (Bergersen et al., 2003). In adulthood, markers of the GABAergic phenotype disappear but they can be transiently expressed during seizures (Gutierrez and Heinemann, 2001; Romo-Parra et al., 2003). Here the release of GABA would counteract the enhanced excitability induced by epileptic activity (Jaffe and Gutiérrez, 2007).
In the immediate postnatal period, GABA appears to be the only neurotransmitter released from MF terminals. We used minimal stimulation of granule cells in the dentate gyrus to activate only one or a few presynaptic fibres (Jonas et al., 1993; Allen and Stevens, 1994). With this technique, a small stimulating electrode is placed on the granule cell layer and the stimulation intensity is decreased until only a single axon is activated. This is achieved when the mean amplitude of the postsynaptic currents and failure probability remain constant over a range of stimulus intensities near threshold for detecting a response. Small movements of the stimulating electrode $20-30 \mu \mathrm{m}$ away from the initial location, lead to the loss of the evoked response. The example of Figure 1A (left) illustrates averaged traces (successes plus failures) of synaptic currents evoked in a CA3 principal cell in response to activation of granule cells in the dentate gyrus with different stimulation intensities. An abrupt increase in the mean peak amplitude of synaptic currents could be detected by increasing stimulation strength (Figures 1A,B; left).

This all or none behaviour suggests that only a single fibre was stimulated. In addition, the latency and the shape of individual synaptic responses remained constant for repeated stimuli and when the extracellular $\mathrm{Ca}^{2+} / \mathrm{Mg}^{2+}$ concentration ratio was reduced from $2: 1.3$ to $1: 3$ further supporting the monosynaptic nature of synaptic currents (Safiulina et al., 2006). Unitary responses elicited
A

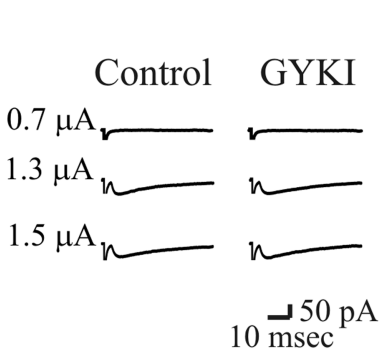

C
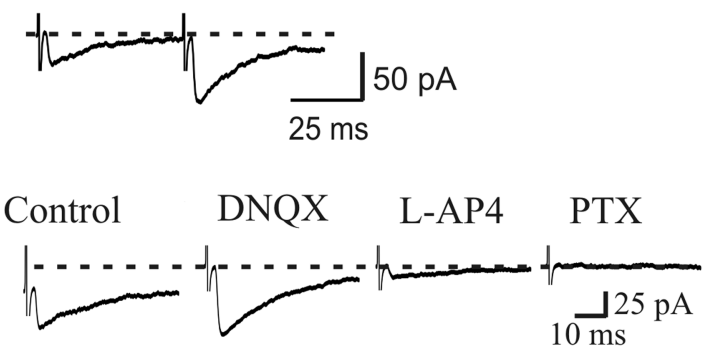

B

Control
GYKI

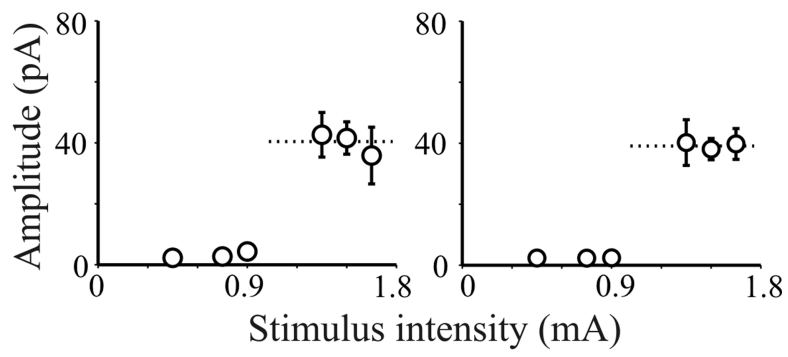

D

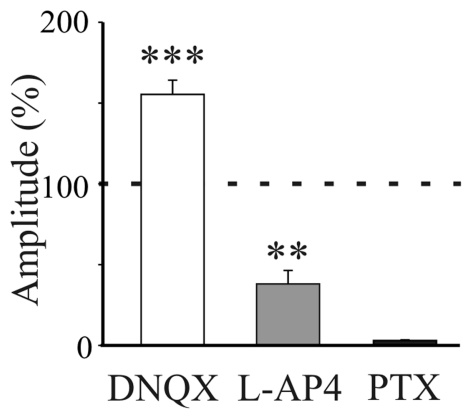

FIGURE 1 |AMPA receptors do not contribute to unitary postsynaptic currents evoked in CA3 principal cells by minimal stimulation of granule cells in the dentate gyrus. (A) Unitary synaptic currents evoked in a CA3 pyramidal cell at $\mathrm{P} 4$ with different stimulation intensities before (Control) and during application of GYKI $52466(30 \mu \mathrm{M})$. Each trace is the average of 15-20 responses (including failures). (B) Peak amplitudes of synaptic currents represented in (A) are plotted as a function of stimulus intensities. Bars are
SEM, dashed lines represent the averaged amplitude of GPSCs. (C) upper trace: MF-GPSCs evoked in a P3 principal cell by minimal stimulation of stratum granulosum in the dentate gyrus exhibit paired-pulse facilitation. Lower traces: MF-GPSCs recorded in the presence of GYKI were enhanced in amplitude by DNQX $(50 \mu \mathrm{M})$, reduced by L-AP4 $(10 \mu \mathrm{M})$ and abolished by PTX $(100 \mu \mathrm{M})$. Each trace is the average of 30 traces. (D) Summary data obtained from 15 neurons. ${ }^{* *} p<0.01 ;{ }^{* *} p<0.001$. Modified from Caiati et al., 2010. 
by stimulation of stratum granulosum in the dentate gyrus could be attributed to MF inputs since they exhibited strong paired-pulse facilitation in response to two stimuli applied $50 \mathrm{~ms}$ apart and short-term frequency-dependent facilitation (Salin et al., 1996; Figures 1C and 2A,C). However, while paired-pulse facilitation was a constant finding (many cells did not respond to the first stimulus but exhibited only few responses to the second one implying that they were "presynaptically" silent), the magnitude of frequencydependent facilitation was dependent on the age of the animals. While at P2-P3 this was rather mild reaching at maximum 200\% of controls, at P5-P6 it reached 400\% (Figure 2).

MF-evoked synaptic currents were also identified on the basis of their sensitivity to group III mGluR agonist 2-amino-4-phosphonobutyric acid (L-AP4; Figures 1C,D). In this regard, neonatal rats behave differently from adult animals which are sensitive to (2S,2'R,3'R)-2-(2',3'-Dicarboxycyclopropyl) glycine (DCG-IV; Kamiya et al., 1996) but insensitive to L-AP4 (Lanthorn et al., 1984). It should be stressed however, that both group II and III mGluRs have been found on rat MF terminals: while group III mGluRs are located predominantly near presynaptic active zones, group II in preterminal rather than terminal portions of axons (Shigemoto et al., 1997). The inability of DCG-IV in modulating
MF responses in immature neurons could be attributed to the different expression and/or location of group II/III mGluRs early in postnatal development.

MF-evoked unitary synaptic currents were insensitive to GYKI $(30 \mu \mathrm{M})$ which at this concentration completely blocks AMPA receptors, indicating that activation of these receptors does not contribute to synaptic currents (Figures 1A,B). However, GABA $A_{A}^{-}$ mediated postsynaptic currents (GPSCs) were reversibly enhanced by DNQX ( $50 \mu \mathrm{M}$; Figures 1C,D) which blocks both AMPA and kainate receptors. GPSCs were completely blocked by GABA receptor antagonists picrotoxin $(100 \mu \mathrm{M})$, bicuculline $(10 \mu \mathrm{M})$ or gabazine $(10 \mu \mathrm{M})$, demonstrating that indeed they were $\mathrm{GABA}_{\mathrm{A}}$-mediated (Safiulina et al., 2006; Sivakumaran et al., 2009; Figures 1C,D). As expected for GABA-mediated events, MF-GPSCs were potentiated by NO-711, a blocker of the GABA transporter GAT-1 and by flurazepam, an allosteric modulator of GABA receptors (Safiulina et al., 2006). Moreover, pressure application of glutamate to granule cells dendrites in stratum moleculare (in the presence of DNQX to prevent the recruitment of GABAergic interneurons by glutamate) induced in targeted cells barrages of L-AP4 sensitive currents that were completely abolished by picrotoxin. It is therefore likely that NMDA-induced depolarization of granule cells dendrites causes
A

P2-P3
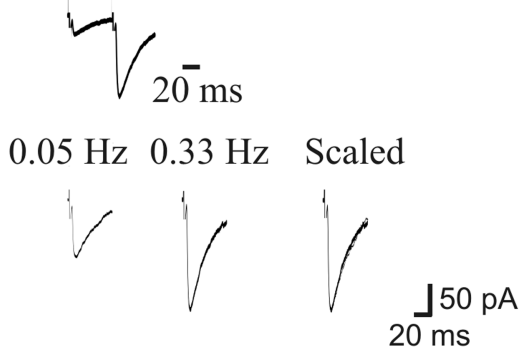

C

P5-P6

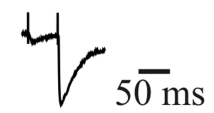

$0.05 \mathrm{~Hz} 0.33 \mathrm{~Hz}$

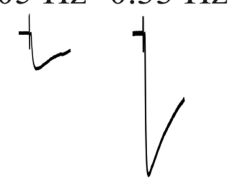

B

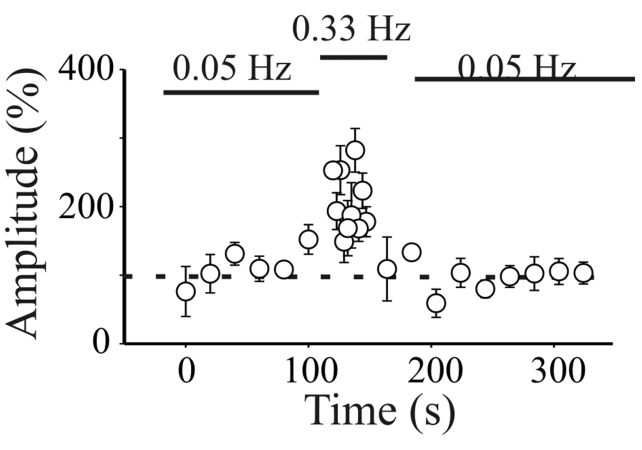

D

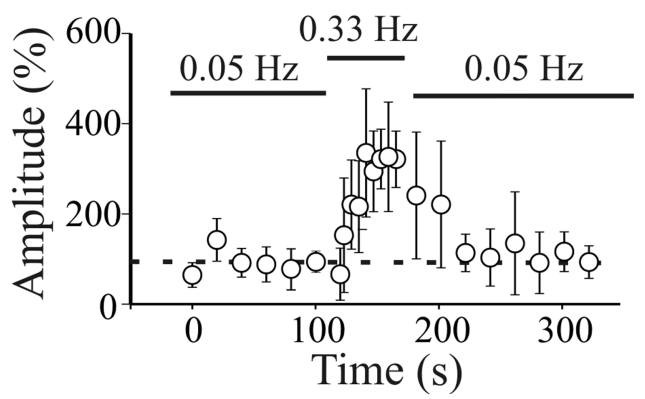

amplitude of synaptic currents evoked in 6 pyramidal cells at 0.05 and $0.33 \mathrm{~Hz}$ (bars) is plotted against time. Note the slow build-up of facilitation of synaptic responses at $0.33 \mathrm{~Hz}$ that completely reversed to control values after returning to $0.05-\mathrm{Hz}$ stimulation. Bars represent SEM. $(\mathbf{C}, \mathbf{D})$ as in $(\mathbf{A}, \mathbf{B})$ but for neurons recorded at P5-P6. (C,D) modified from Safiulina et al., 2006.
(A) Upper trace: MF-GPSCs exhibiting strong paired-pulse facilitation in response to two stimuli (50 $\mathrm{ms}$ apart) delivered to the granule cells in the dentate gyrus (P3). Lower traces represent averaged responses (including failures) obtained at 0.05 and $0.33 \mathrm{~Hz}$ from the same neuron. (B) The mean 
the release of GABA from MF terminals. Blocking NMDA receptors with D-APV prevented the effects of chemical stimulation of granule cell dendrites on CA3 principal cells. Moving the pressure pipette few $\mu \mathrm{m}$ away towards the hilus to activate hilar interneurons caused barrage of synaptic currents that were insensitive to L-AP4 but were blocked by picrotoxin, implying that they were mediated by the release of GABA from GABAergic interneurons (Safiulina et al., 2006).

In contrast to MF-GPSCs, synaptic currents mediated by GABA released from GABAergic interneurons were insensitive to L-AP4 but were blocked by bicuculline or picrotoxin. They occurred with high probability and exhibited a strong paired-pulse depression in response to two closely spaced stimuli.

Towards P5-P6, additional fibres releasing both glutamate and GABA into CA3 principal cells could be recruited. These responses intermingled with failures and fluctuating between outwards, biphasic and inwards were sensitive to L-AP4 and were abolished by the respective receptor antagonists (Safiulina et al., 2006). The possibility of releasing different neurotransmitters from the same fibre has been well documented in the retina (O'Malley and Masland, 1989) and the spinal cord (Jonas et al., 1998). In particular, GABA has been reported to be released with glutamate from MF terminals of juvenile rats (Gutierrez et al., 2003) or guinea pigs (Walker et al., 2001) and glutamate from inhibitory terminals in the lateral superior olive of the developing auditory system (Gillespie et al., 2005).

GABA RELEASED FROM MF TERMINALS DEPOLARIZES PRINCIPAL CELLS To evaluate whether GABA released from MFs exerts a depolarizing or a hyperpolarizing action in principal cells, $\mathrm{GABA}_{\mathrm{A}}$-mediated postsynaptic potentials (GPSPs) were recorded with gramicidinperforated patch to preserve the anionic conditions of the recorded cells. Using this method, we found that on average GPSPs reversed at a potential more positive that the resting membrane potential $\left(\mathrm{E}_{\mathrm{GPSP}}:-47.6 \pm 3.3 \mathrm{mV} ; \mathrm{V}_{\mathrm{R}}:-56 \pm 2.2 \mathrm{mV}\right.$ ) indicating that GABA exerts a depolarizing action (Sivakumaran et al., 2009; see also Sipilä et al., 2006; Tyzio et al., 2007). To see whether accumulation of chloride inside the cell via the cation-chloride co-transporter NKCC1 was responsible for the depolarizing action of GABA, slices were incubated with bumetanide, a selective inhibitor of NKCC1 (Dzhala et al., 2005; Sipilä et al., 2006). Bumetanide caused a slight membrane hyperpolarization and a shift of $\mathrm{E}_{\mathrm{GPSP}}$ towards values more negative than $\mathrm{V}_{\mathrm{R}}\left(\mathrm{E}_{\mathrm{GPSP}}:-71.5 \pm 3.09 \mathrm{mV} ; \mathrm{V}_{\mathrm{R}}:-63.6 \pm 2.3 \mathrm{mV}\right)$. These data demonstrate that at birth, due to the low expression of the KCC2 extruder, $\mathrm{Cl}^{-}$accumulates inside the cell via NKCC1 leading to a membrane depolarization.

Interestingly, the value of $\mathrm{E}_{\mathrm{GPSP}}$ was very close to the threshold for action potential generation $(-49.3 \pm 2.4 \mathrm{mV})$ suggesting that GABA may also be excitatory. To see whether synaptic stimulation of granule cells in the dentate gyrus could initiate action potentials in CA3 pyramidal neurons, experiments were performed in cellattach mode to maintain the intracellular milieu of principal cells intact. Synaptic stimulation of MF in stratum lucidum elicited in 2/9 cases action potentials in CA3 principal cells (Figure 3A), an effect that was blocked by picrotoxin $(100 \mu \mathrm{M})$ indicating that was mediated through the activation of $\mathrm{GABA}_{\mathrm{A}}$ receptors (Figure 3A). Furthermore, bath application of the GABA agonist isoguvacine
$(3 \mu \mathrm{M})$ to whole cell patched CA3 principal cells under current clamp conditions, increased the frequency of GDPs in seven out of ten CA3 principal cells (from $0.08 \pm 0.02 \mathrm{~Hz}$ to $0.15 \pm 0.04 \mathrm{~Hz}$; $n=7 / 10 ; p<0.01$; Figure 3B). These results indicate that GABA released from MF terminals not only depolarizes CA3 principal cells but in some cases also excites them, thus overwhelming the concomitant shunting effect of this neurotransmitter (see also Tyzio et al., 2007).

Whether GABA is released from low threshold GABAergic cells (Uchigashima et al., 2007) which early in development are supposed to migrate to the upper and middle portions of the granule cell layer (Dupuy and Houser, 1997) or by glutamatergic cells synthesising GABA which would be downregulated in adulthood (Frahm and Draguhn, 2001) it remains to be elucidated. It is clear however, that in spite of their origin, synaptic responses elicited at birth by granule cells stimulation in the dentate gyrus maintain most of the functional properties of later appearing glutamatergic MF responses.

\section{GABA RELEASE FROM MF TERMINALS IS REGULATED BY PRESYNAPTIC GABA ${ }_{B}$ AND KAINATE RECEPTORS}

In adulthood, MFs are endowed with a number of receptor types whose activation regulates glutamate release. These include metabotropic glutamate receptors (Kamiya et al., 1996),

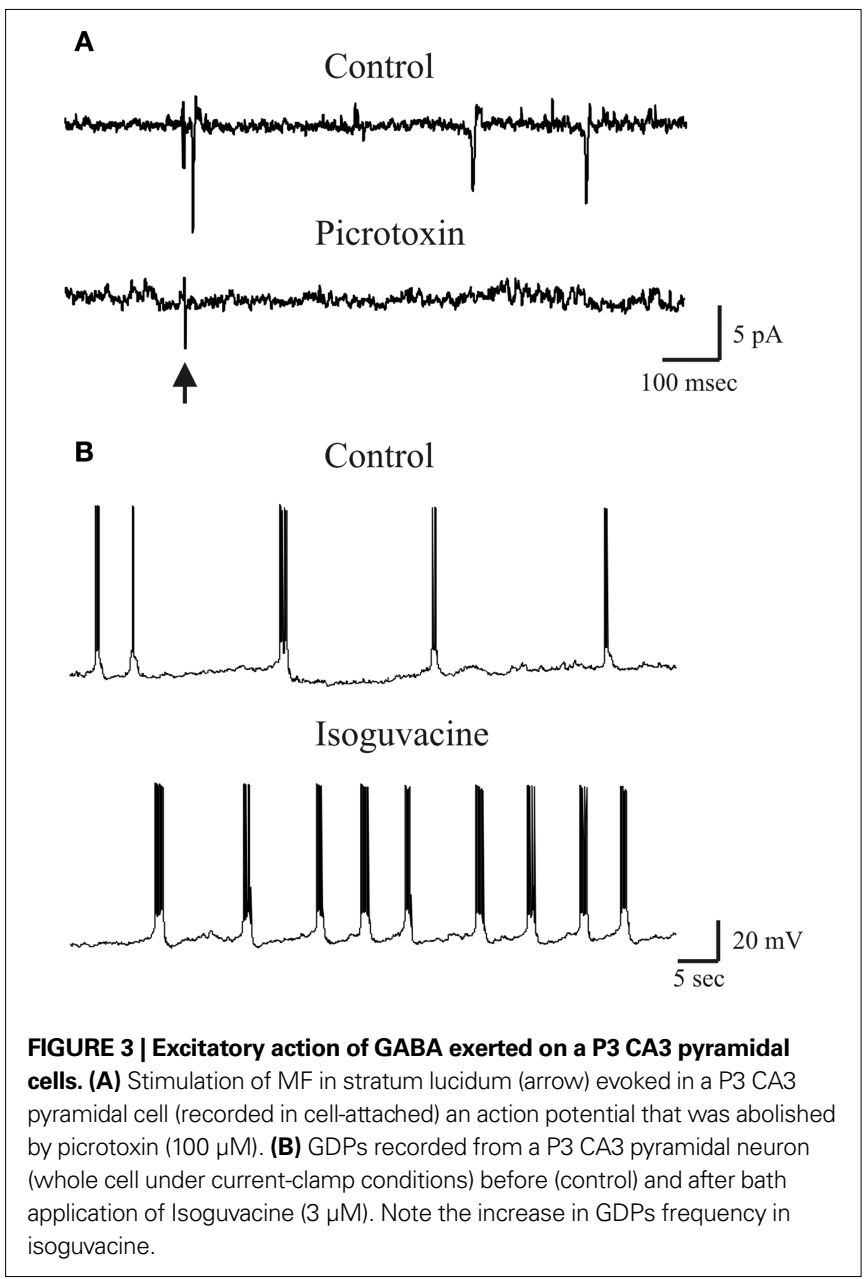


kainate receptors (Castillo et al., 1997; Vignes and Collingridge, 1997), adenosine receptors (Thompson et al., 1992), peptides (Weisskopf et al., 1993), GABA (Trigo et al., 2008) and GABA receptors (Min et al., 1998; Vogt and Nicoll, 1999). As already mentioned immature MF-GPSCs were reduced in amplitude by L-AP4, a group III mGluR agonist, and enhanced by DNQX (applied in the presence of the AMPA receptor antagonist GYKI) suggesting the involvement of mGlu and kainate receptors in their regulation.

The presence of ionotropic $\mathrm{GABA}_{\mathrm{A}}$ receptors on MF terminals has been unambiguously demonstrated by Alle and Geiger (2007) who, using patch clamp recordings from single MF boutons, detected $\mathrm{GABA}_{\mathrm{A}}$-activated currents following local application of GABA from a puff pipette. While in 3 to 4 -weeks-old guinea pigs activation of presynaptic MF GABA $A_{A}$ receptors by ambient GABA or GABA spillover from neighboring interneurons led to a reduction of MFs excitability (Ruiz et al., 2003), in juvenile rats led to a depolarization of MF terminals and to an increase in cell firing (Nakamura et al., 2007). Whether a similar effect may occur during the first week of postnatal life when MFs release GABA is unknown. However, experiments from immature glutamatergic Schaffer collateral-CA1 synapses have unveiled a decreased in cell excitability after bath application of picrotoxin, suggesting that tonic activation of presynaptic $\mathrm{GABA}_{\mathrm{A}}$ receptors localized on glutamatergic terminals may account for the observed effects (Marchionni et al., 2007).

In neonates, spillover of GABA from MF terminals down regulates its own release also via presynaptic $\mathrm{GABA}_{\mathrm{B}}$ receptors. In addition, evidence has been recently provided that GABA released can be down regulated by presynaptic kainate receptors activated by glutamate present in the extracellular space. Activation of both $\mathrm{GABA}_{\mathrm{B}}$ and kainate receptors may often lead to synapse silencing.

Synapses can be silent via both post and presynaptic mechanisms. "Postsynaptically" silent synapses are unable to detect the neurotransmitter release because they lack the respective receptors on the subsynaptic membrane (Malenka and Nicoll, 1997; Malinow et al., 2000; Kerchner and Nicoll, 2008). "Presynaptically" silent connections are those in which the probability of transmitter release or the concentration of the transmitter in the cleft is too low to produce a detectable quantal response (Voronin and Cherubini, 2004). Silent synapses are common during postnatal development in the hippocampus. However, while at glutamatergic synapses both post and presynaptically silent synapses have been observed (Durand et al., 1996; Gasparini et al., 2000; Montgomery et al., 2001), at GABAergic connections mainly presynaptically silent ones have been detected (Kannenberg et al., 1999; Kasyanov et al., 2004; Bekkers, 2005; Safiulina and Cherubini, 2009).

\section{PRESYNAPTIC GABA ${ }_{\mathrm{B}}$ RECEPTORS}

While postsynaptic $\mathrm{GABA}_{\mathrm{B}}$ receptors are poorly expressed at birth and start appearing towards the end of the first postnatal week, presynaptic $\mathrm{GABA}_{\mathrm{B}}$ receptors are already present and functional (Gaiarsa et al., 1995; Lei and McBain, 2003). As shown in Figures $4 A, B$, application of the selective $\mathrm{GABA}_{\mathrm{B}}$ receptor antagonist CGP55845 $(1 \mu \mathrm{M})$ to a presynaptically silent neuron induced the appearance of synaptic responses. Overall, in ten neurons CGP55845 significantly increased the amplitude of GPSCs (from $6.6 \pm 2.5 \mathrm{pA}$ to $13.4 \pm 3.5 \mathrm{pA} ; p<0.05$ ) and the successes rate (from $14.5 \pm 5.7 \%$ to $41.5 \pm 11.2 \%, p<0.05$ ). In addition, in seven non-silent cells, CGP55845 reduced the PPR (the ratio between the amplitude of the second response over the first, from $6.4 \pm 1.9$ to $3.1 \pm 1.3$ and increased the $\mathrm{CV}^{-2}$ from $0.3 \pm 0.1$ to $1.5 \pm 0.4)$ in the absence of any change in holding current or membrane input resistance (Figure 4E, white columns). This indicates that activation of $\mathrm{GABA}_{\mathrm{B}}$ autoreceptors by spillover of GABA from MF terminals down regulates GABA release and contributes to switching off conductive synapses making them silent.

In contrast, the $\mathrm{GABA}_{\mathrm{B}}$ receptor agonist baclofen induced a powerful depression of MF-GPSCs, an effect that was associated with a significant increase in transmitter failures and in the paired-pulse ratio. Interestingly, the $\mathrm{IC}_{50}$ value for baclofen $(400 \mathrm{nM})$ was at least one order of magnitude lower than that found at GABAergic synapses in CA3 stratum radiatum interneurons (Lei and McBain, 2003). This may be related to differences in $\mathrm{GABA}_{B}$ receptors expression, distribution, and/or affinity among different cell types and suggests a target-specific modulation of GABAergic signaling by $\mathrm{GABA}_{\mathrm{B}}$ autoreceptors.

Furthermore, by increasing the concentration of GABA in the extracellular space by stimulating the MFs at $3-10 \mathrm{~Hz}$ or by blocking GABA uptake with NO711, a selective blocker of the GABA transporter GAT-1, resulted, in the majority of cases in synaptic depression that was rescued by CGP55845, further suggesting the involvement of $\mathrm{GABA}_{\mathrm{B}}$ receptors in reducing the probability of GABA release leading sometimes to synapses silencing (Safiulina and Cherubini, 2009).

\section{PRESYNAPTIC KAINATE RECEPTORS}

A recent study from our laboratory has provided evidence that at immature MF-CA3 synapses GABAergic signalling is modulated by presynaptic kainate receptors (Caiati et al., 2010). Among the kainate receptor subtypes expressed in the immature hippocampus GluK1 seems to exert a powerful control on transmitter release (Bettler et al., 1990; Bahn et al., 1994; Ritter et al., 2002; Lauri et al., 2006). In a previous work performed on hippocampal slices from neonatal animals, Lauri et al. (2005) have demonstrated that GluK1 contributes to modulate spontaneous, network-driven giant depolarizing potentials or GDPs, which are generated by the synergistic action of glutamate and GABA, that at this developmental stage is depolarizing and excitatory (BenAri et al., 2007). Thus, we tested whether GluK1 can modulate GABA release from MF terminals. The selective GluK1 kainate receptor antagonist UBP $302(10 \mu \mathrm{M})$, applied in the bath in the presence of GYKI $(30 \mu \mathrm{M})$, reversibly enhanced the amplitude of GPSCs (from $48 \pm 8 \mathrm{pA}$ to $84 \pm 15 \mathrm{pA} ; n=19 ; p=0.001$ ) and the successes rate (from $0.4 \pm 0.04$ to $0.7 \pm 0.03 ; p=0.001$ ). These effects were associated with a significant decrease in PPR (from $1.4 \pm 0.2$ to $0.6 \pm 0.1 ; p=0.001)$ and a significant increase in $\mathrm{CV}^{-2}$ (from $0.97 \pm 0.2$ to $3.3 \pm 0.9 ; p=0.001$ ) indicating a presynaptic type of action (Figure 4E, black columns). In addition, in six "presynaptically" silent cases, UBP 302 induced the appearance of synaptic responses to the first stimulus suggesting that 


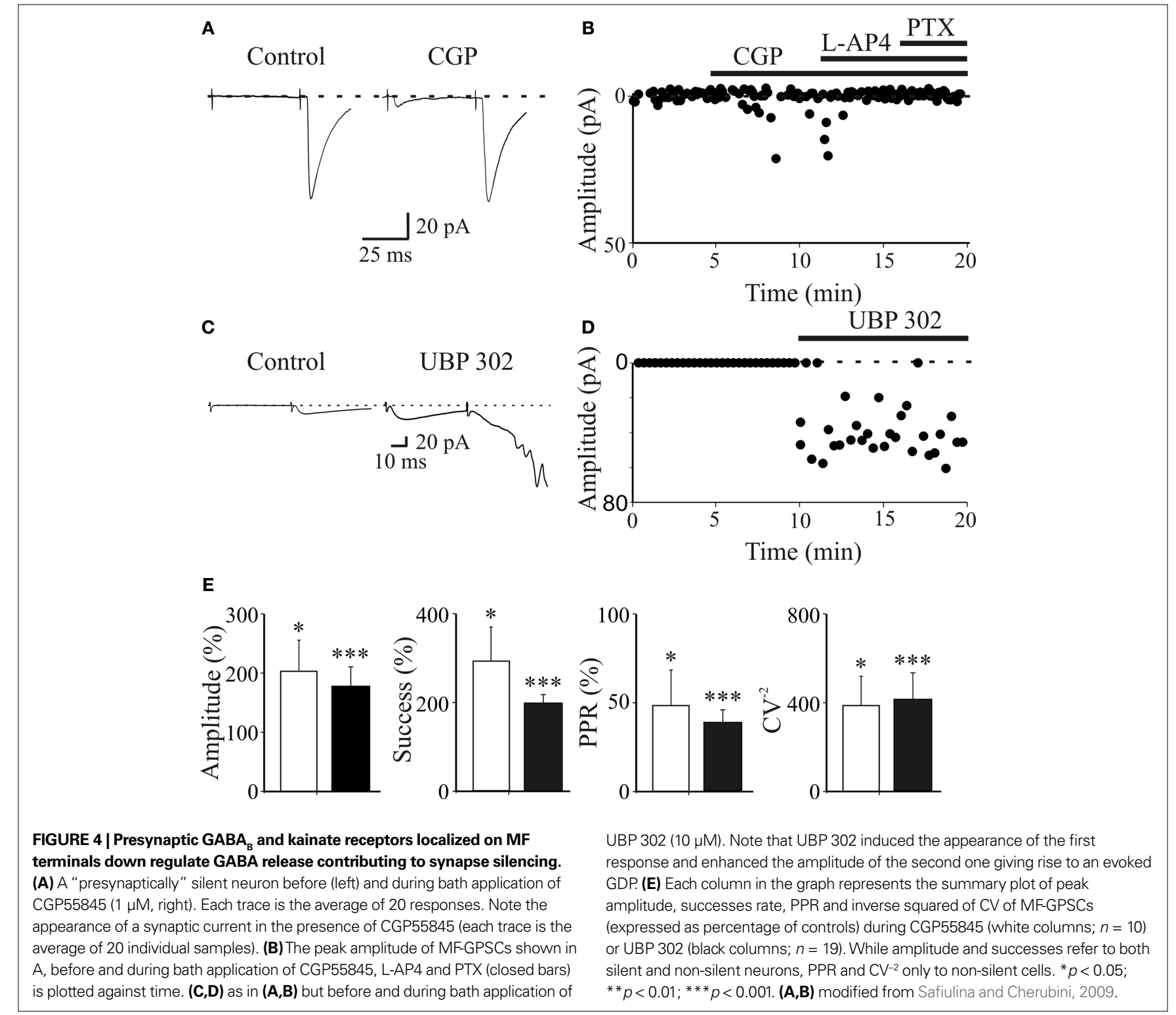

endogenous activation of GluK1 contributes to switching off conductive synapses (Figures 4C,D). The depression of MF-GPSCs by kainate receptors was not indirectly mediated via other signalling molecules known to inhibit GABA release, since the potentiating effect of the kainate antagonist on GPSCs persisted in the presence of $\mathrm{GABA}_{\mathrm{B}}$, nicotinic, muscarinic, $\mathrm{P} 2 \mathrm{Y}$ and mGluR antagonists (Caiati et al., 2010).

One obvious question is how could presynaptic GluK1 receptors be activated if the main neurotransmitter released from MF is GABA? One possibility is that GluK1 receptors are activated by endogenous glutamate present in the extracellular space. A less efficient glutamate transport mechanism and a poorly developed diffusional barrier in neonates (Danbolt, 2001) would facilitate the maintenance of a relatively high glutamate concentration in the extracellular space. To test whether this was the case, we used an enzymatic glutamate scavenger system (Overstreet et al., 1997;
Min et al., 1998) which catalyzes the conversion of glutamate and pyruvate to $\alpha$-ketoglutarate and alanine. By enhancing the clearance of glutamate from the extracellular space, the scavenger prevented the activation of presynaptic kainate receptors and similarly to UBP 302 induced an increase in amplitude (from $44 \pm 8 \mathrm{pA}$ and $73 \pm 10 \mathrm{pA}$ ) and in successes rate (from $0.5 \pm 0.1$ to $0.8 \pm 0.1 ; p=0.01)$ of GPSCs. Like UBP 302, this effect was associated with a significant decrease in PPR (from $1.5 \pm 0.2$ to $0.7 \pm 0.1 ; n=7 ; p=0.008$ ), and a significant increase in $\mathrm{CV}^{-2}$ (from $1.02 \pm 0.2$ to $3.4 \pm 0.94 ; n=7 ; p=0.01$ ), further suggesting a presynaptic site of action. In addition, the facilitating effect of the scavenger on GPSCs was fully occluded by subsequent application of UBP 302.

These data indicate that early in postnatal life, depression of GABA release from MF terminals occurs via activation of GluK1 receptors by endogenous glutamate present in the extracellular space. 


\section{CALCIUM TRANSIENTS ASSOCIATED WITH GDPS ACT AS A COINCIDENT DETECTOR SIGNALS FOR ENHANCING SYNAPTIC EFFICACY AT MF-CA3 SYNAPSES}

Correlated network activity such as GDPs constitutes a hallmark of developmental networks, well preserved during evolution (Ben-Ari et al., 1989). GDPs which have been proposed to be the in vitro counterpart of "sharp waves" recorded in rat pups during immobility periods, sleep and feeding (Leinekugel et al., 2002) can be considered a primordial form of synchrony between neurons, which precedes more organized forms of activity such as the theta and the gamma rhythms (Buzsaki and Draguhn, 2004). GDPs and associated calcium signalling are crucial for several developmental processes including synaptogenesis (Kasyanov et al., 2004; Ben-Ari et al., 2007; Mohajerani et al., 2007).

To assess whether GDPs are able to modify MF-CA3 connections in an associative type of manner, we have developed a "pairing" procedure consisting in correlating calcium transients generated by GDPs with MF activation (Kasyanov et al., 2004). To this purpose, after a control period of 5-10 min, the patch was switched from voltage-clamp to current-clamp mode and MF-evoked GPSCs were paired for 5 min with GDPs.

"Pairing" consisted in triggering MF stimulation with the rising phases of GDPs (Figures 5A,B). After this period the patch was switched back to voltage-clamp mode and synaptic currents were recorded as in control for a prolonged period of time (at least $30 \mathrm{~min}$ ). As illustrated in Figures 5C,D, in the case of presynaptically silent synapses (Gasparini et al., 2000), the pairing protocol caused the appearance of responses to the first stimulus and increased the number of successes to the second one. In the case of non-silent low probability synapses, the pairing procedure produced a strong and persistent potentiation of MF responses, which was associated with a significant increase in the number of successes and a significant reduction in the paired-pulse ratio, suggesting that an increased probability of transmitter release accounts for the persistent increase in synaptic efficacy.

When the interval between GDPs and MF stimulation was progressively increased, synaptic potentiation declined and reached control level 2-3 s after GDPs onset. In the absence of pairing, no significant changes in synaptic efficacy could be detected. Pairing-induced long-lasting changes in synaptic efficacy involved elevation of calcium via voltage-gated calcium channels because it was suppressed by nifedipine, that blocks L-type of voltage-dependent calcium channels or by loading the cell with BAPTA that chelates calcium ions (Kasyanov et al., 2004).

In conclusions, during development, coincident detection signals provided by GDPs could be crucial for enhancing synaptic transmission at emerging MF-CA3 connections. How this contributes to wiring assembly and to the establishment of appropriate synaptic connections remains to be elucidated.

\section{WHY GABA AND NOT GLUTAMATE?}

In the adult hippocampus, MFs provide a strong excitatory input to CA3 pyramidal cells. Under certain conditions they may act as "conditional detonators" able to discharge principal cells in a temporally and spatially precise way, their relative strength being

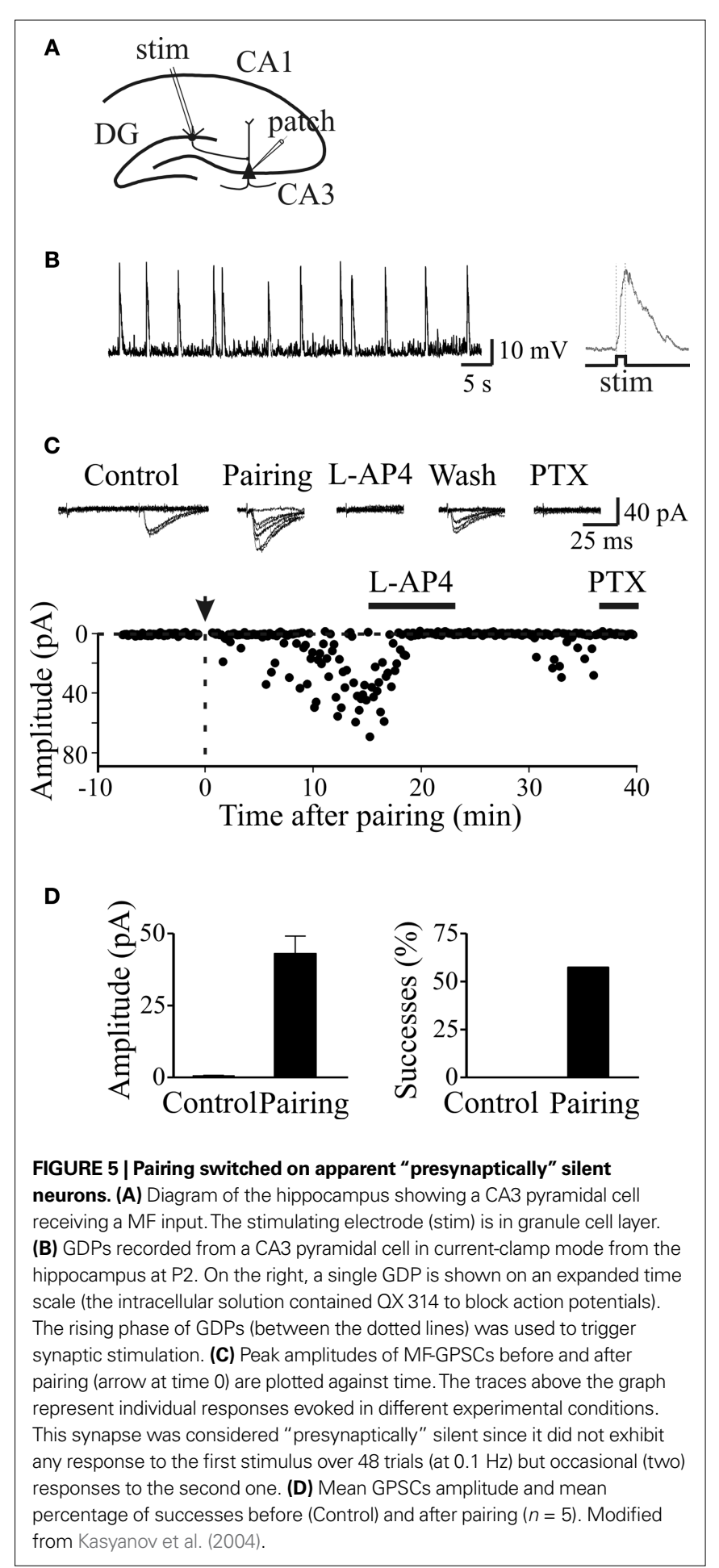

dynamically regulated by the activity of granule cells, CA3 pyramidal neurons and cells in the entorhinal cortex (Henze et al., 2000; Urban et al., 2001). Excitation may be limited by the inhibitory influence of GABA released by a large population of interneurons innervated by MF. However, it is unclear how early in postnatal life MF signalling via $\mathrm{GABA}_{\mathrm{A}}$ receptors may influence the CA3 associative network since AMPA and GABA $_{A}$ receptors have 
different biophysical properties. We have thus compared the relative strength of CA3 pyramidal cells output in relation to their MF GABAergic or glutamatergic inputs using a realistic model which takes into account different parameters, including unitary conductance of MF-GPSCs or MF-EPSCs, quantal content, and kinetics of GABA- or AMPA-mediated responses (see Table 1). The model has been simplified, implementing the macroscopic overall conductance changes observed during the experiments. It did not include the expression of postsynaptic NMDA receptors or more detailed mechanisms such as postsynaptic receptor density, neurotransmitter diffusion, reuptake, etc. The presence of equidistant peaks in peak amplitude distribution histograms of MF-GPSCs evoked $0.1 \mathrm{~Hz}$ by minimal stimulation of granule cells in the dentate gyrus, under conditions of low quantal output (by reducing the extracellular $\mathrm{Ca}^{2+} / \mathrm{Mg}^{2+}$ ratio from 1.53 to 0.16 ) was used to estimate the unitary conductance. The representative traces of Figure 6A show selected events (excluding failures) recorded at $-60 \mathrm{mV}$, each of them multiple of the quantal size as obtained from the peak amplitude distribution of the same cell (Figure 6B). The unbinned peak amplitude data were directly fitted with the sum of four Gaussians functions using the expectation-maximization algorithm for parameters estimation (Redman, 1990). The separation of the peaks was $21.7 \mathrm{pA}$ and the SD $6.6 \mathrm{pA}$ (see Jonas et al., 1993).

In three different cells (out of eight) in which amplitude histograms were judged as quantal according to the criteria of the equidistance of peaks and the consistency of the location of the peaks through the data set, the peak separation was $24.1 \pm 4.7 \mathrm{pA}$. Assuming a reversal potential for GABA of $-44 \mathrm{mV}$ (Sivakumaran et al., 2009) the corresponding apparent quantal conductance was $1.5 \mathrm{nS}$. Interestingly, the quantal size value obtained in the present experiments was similar to that obtained for synapticallyevoked IPSCs in neurons of the granule cell layer in juvenile animals (Edwards et al., 1990). In seven cells recorded under control conditions $\left(\mathrm{Ca}^{2+} / \mathrm{Mg}^{2+}\right.$ ratio of 1.53) the peak GPSC conductance varied from a minimum $1.2 \mathrm{nS}$ to a maximum $13.8 \mathrm{nS}$, suggesting an apparent maximum quantal content of $\sim 10$. In Table 1, these and other parameters for MF-GPSCs and MF-EPSCs have been reported. Some of MF-EPSCs parameters have been taken from Jonas et al. (1993). It is worth mentioning that the firing frequency of granule cells was estimated from the firing rate of spikes

Table 1| Comparison of the relative strength of CA3 pyramidal cells output in relation to their MF GABAergic or glutamatergic inputs.

\begin{tabular}{lll}
\hline & MF-EPSCs & MF-GPSCs \\
\hline $\mathrm{E}_{\text {rev }}$ & $0 \mathrm{mV}$ & $-44 \mathrm{mV}$ \\
Mean (20-80\%) rise time & $0.4 \mathrm{~ms}$ & $1.4 \mathrm{~ms}$ \\
Mean (20-80\%) decay time & $4.8 \mathrm{~ms}$ & $27 \mathrm{~ms}$ \\
Firing frequency & $20-50 \mathrm{~Hz}$ & $20-50 \mathrm{~Hz}$ \\
Unitary conductance & $133 \mathrm{pS}$ & $1.5 \mathrm{nS}$ \\
Maximum peak conductance & $5.5 \mathrm{nS}$ & $13.8 \mathrm{nS}$ \\
Estimated quantal content & $u p ~ t o 50$ & up to 10 \\
MF inputs (randomly activated) & 30 & 30 \\
Spike threshold & $-45 \mathrm{mV}$ & $-45 \mathrm{mV}$
\end{tabular}

occurring at the top of spontaneous GDPs. In addition, we estimated the number of MF inputs impinging into CA3 principal cells equal to 30 on the assumption that during the first week of postnatal life more than one third of MF reach their targets (Gaarskjaer, 1985). In adulthood, each principal cell receives $\sim 50 \mathrm{MF}$ inputs from granule cells.

Thirty synapses were randomly distributed on the proximal apical dendrites (within $100 \mu \mathrm{m}$ from the soma) of a realistic CA3 model neuron (Hemond et al., 2008). The average number of spikes generated by a train of 10 random (poissonian) activations of GABAergic or glutamatergic inputs, at an average frequency of 20 or $40 \mathrm{~Hz}$, was then calculated from 10 simulations. A few typical somatic recordings are shown in Figure 7, and the average $( \pm$ SEM) spikes using GABA or glutamatergic synapses were $12.6 \pm 0.5$ and $7 \pm 0.3$ (at $20 \mathrm{~Hz}$ ), or $8.7 \pm 0.8$ and $5 \pm 0.5$ (at $40 \mathrm{~Hz}$ ), respectively. The model predicts that the more positive reversal potential of glutamatergic synapses can easily cause a strong depolarizing envelope that could transiently hinder the membrane repolarization process, inactivating $\mathrm{Na}$ channels and saturating the cell. In addition to elicit less spikes, with obvious consequences for frequency-dependent synaptic plasticity mechanisms, this effect could generate a number of other problems, ranging from excitotoxicity caused by a much higher elevation in intracellular calcium concentration to receptor desensitization.

Overall, these data strongly suggest that early in postnatal development, in spite of its shunting action, GABA released from MF terminals is able to elicit action potentials in targeted neurons and to convey information into the auto-associative CA3 network. GABA-induced excitation would provide the basis for enhancing synaptic efficacy at emerging synapses in a Hebbian type of way (spike time-dependent plasticity), thus contributing to synaptogenesis and to the establishment of the adult neuronal circuit. The down regulation of GABA

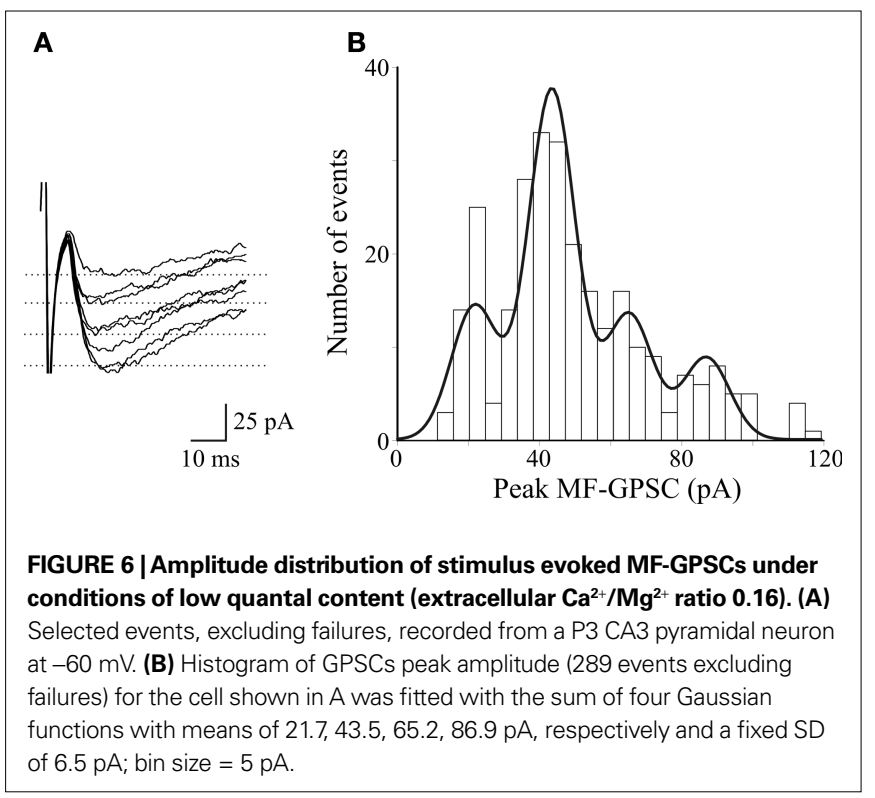




\section{GABA}

$20 \mathrm{~Hz}$

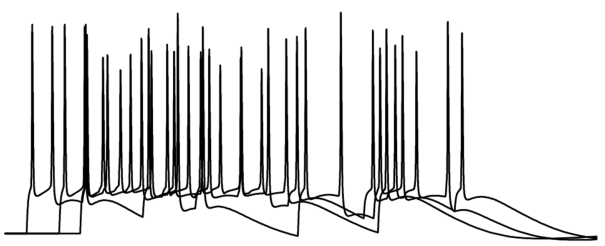

$40 \mathrm{~Hz}$

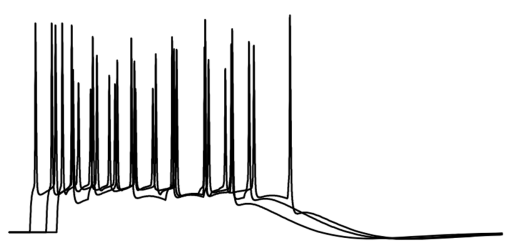

\section{Glutamate}

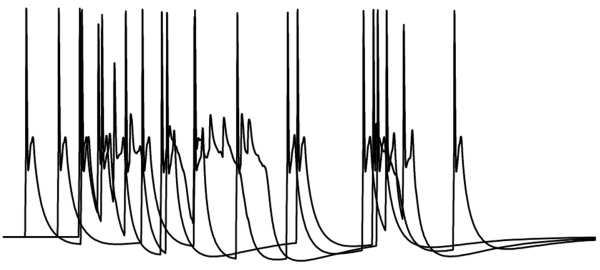

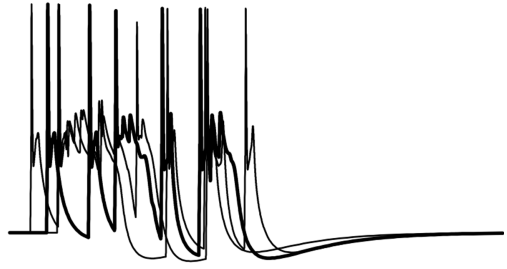

$20 \mathrm{mV}$

$100 \mathrm{~ms}$

FIGURE 7 | Effects of GABAergic or glutamatergic synapses on a model neuron. Typical traces of somatic membrane potential are plotted during three simulations activating 30 synaptic inputs at an average frequency of $20 \mathrm{~Hz}$ (left) or $40 \mathrm{~Hz}$ (right), using GABAergic (top) or glutamatergic (bottom) synapses. The same stimulation pattern was used in both cases. The passive and active properties of the neuron were those used in a previous work, in a configuration that reproduced the experimental properties of CA3 cells showing firing adaptation (see Figure $9 \mathrm{E}$ in Hemond et al., 2008), adjusted to take into account the lower spike threshold $(-45 \mathrm{mV})$ observed in early development in these neurons (Sivakumaran et al., 2009). The model files are available for download from the ModelDB section of the Senselab database (http://senselab.med. yale.edu). release exerted by activation of $\mathrm{GABA}_{\mathrm{B}}$ and kainate receptors localized on MF terminals would in turn limit the excessive activation of the CA3 network and would prevent the development of seizures.

\section{REFERENCES}

Acsády, L., Kamondi, A., Sik, A., Freund, T., and Buzsaki, G. (1998). GABAergic cells are the major postsynaptic targets of mossy fibers in the rat hippocampus. J. Neurosci. 18, 3386-3403.

Alle, H., and Geiger, J. R. (2007). GABAergic spill-over transmission onto hippocampal mossy fiber boutons. J, Neurosci. 27, 942-950.

Allen, C., and Stevens, C. F. (1994). An evaluation of causes for unreliability of synaptic transmission. Proc. Natl. Acad. Sci. U.S.A. 91, 10380-10383.

Amaral, D. G., and Dent, J. A. (1981). Development of the mossy fibers of the dentate gyrus: I. A light and electron microscopic study of the mossy fibers and their expansions. J. Comp. Neurol. 195, 51-86.
Bahn, S., Volk, B., and Wisden, W. (1994). Kainate receptor gene expression in the developing rat brain. J. Neurosci. 14, 5525-5547.

Bekkers, J. M. (2005). Presynaptically silent GABA synapses in hippocampus. J. Neurosci. 25, 4031-4039.

Ben-Ari, Y., Cherubini, E., Corradetti, R. and Gaiarsa, J. L. (1989). Giant synaptic potentials in immature rat $\mathrm{CA} 3$ hippocampal neurones. J. Physiol.416, 303-325.

Ben-Ari, Y., Gaiarsa, J. L., Tyzio, R., and Khazipov, R. (2007). GABA: a pioneer transmitter that excites immature neurons and generates primitive oscillations. Physiol. Rev. 87, 1215-1284.

Bergersen, L., Ruiz, A., Bjaalie, J. G, Kullmann, D. M., and Gundersen, V. (2003). GABA and GABAA receptors

\section{ACKNOWLEDGMENTS}

We thank Prof. V. Torre for critically reading the manuscript. This work was supported by a grant from Ministero Istruzione Universita' e Ricerca (MIUR) to Enrico Cherubini.

at hippocampal mossy fibre synapses. Eur. J. Neurosci. 18, 931-941.

Bettler, B., Boulter, J., HermansBorgmeyer, I., O'Shea-Greenfield, A., Deneris, E. S., Moll, C., Borgmeyer U., Hollmann, M., and Heinemann, S. (1990). Cloning of a novel glutamate receptor subunit, GluR5: expression in the nervous system during development. Neuron 5, 583-595.

Bischofberger, J., Engel, D., Frotscher, M. and Jonas, P. (2006). Timing and efficacy of transmitter release at mossy fiber synapses in the hippocampal network. Pflugers Arch. 453, 361-372.

Buzsaki, G., and Draguhn, A. (2004) Neuronal oscillations in cortical networks. Science 304, 1926-1929.

Caiati, M. D., Sivakumaran, S., and Cherubini, E. (2010). In the developing rat hippocampus, endogenous activation of presynaptic kainate receptors reduces GABA release from mossy fiber terminals. J. Neurosci. 30, 1750-1759.

Castillo, P. E., Malenka, R. C., and Nicoll, R. A. (1997). Kainate receptors mediate a slow postsynaptic current in hippocampal CA3 neurons. Nature 388, 182-186.

Danbolt, N.C. (2001). Glutamate uptake. Prog. Neurobiol. 65, 1-105.

Dupuy, S. T., and Houser, C. R. (1997). Developmental changes in GABA neurons of the rat dentate gyrus: an in situ hybridization and birthdating study. J. Comp. Neurol. 389, 402-418.

Durand, G. M., Kovalchuk, Y., and Konnerth, A. (1996). Long-term potentiation and functional synapse 
induction in developing hippocampus. Nature 381, 71-75.

Dzhala, V. I., Talos, D. M., Sdrulla, D. A., Brumback, A. C., Mathews, G. C., Benke, T. A., Delpire, E., Jensen, F. E., and Staley, K. J. (2005). NKCC1 transporter facilitates seizures in the developing brain. Nat. Med. 11, 1205-1213.

Edwards, F.A., Konnerth, A. and Sakmann, B. (1990). Quantal analysis of inhibitory synaptic transmission in the dentate gyrus of rat hippocampal slices: a patch-clamp study. J. Physiol. 430, 213-249.

Frahm, C., and Draguhn, A. (2001). GAD and GABA transporter (GAT1) mRNA expression in the developing rat hippocampus. Brain Res. Dev. Brain Res. 132, 1-13.

Frotscher, M., Jonas, P., and Sloviter, R. S. (2006). Synapses formed by normal and abnormal hippocampal mossy fibers. Cell Tissue Res. 326, 361-367.

Gaarskjaer, F. B. (1985). The development of the dentate area and the hippocampal mossy fiber projection of the rat. J. Comp. Neurol. 241, 154-170.

Gaiarsa, J. L., Tseeb, V., and Ben-Ari, Y. (1995). Postnatal development of preand postsynaptic GABAB-mediated inhibitions in the CA3 hippocampal region of the rat. J. Neurophysiol. 73, 246-255.

Gasparini, S., Saviane, C., Voronin, L. L., and Cherubini, E. (2000). Silent synapses in the developing hippocampus: lack of functional AMPA receptors or low probability of glutamate release? Proc. Natl. Acad. Sci. U.S.A. 97, 9741-9746.

Gillespie, D. C., Kim, G., and Kandler, K. (2005). Inhibitory synapses in the developing auditory system are glutamatergic. Nat. Neurosci. 8, 332-338.

Gómez-Lira, G., Lamas, M., RomoParra, H., and Gutiérrez, R. (2005). Programmed and induced phenotype of the hippocampal granule cells. $J$. Neurosci. 25:6939-6946.

Gutierrez, R., and Heinemann, U. (2001). Kindling induces transient fast inhibition in the dentate gyrus-CA3 projection. Eur. J. Neurosci. 13, 1371-1379.

Gutierrez, R., Romo-Parra, H., Maqueda, J., Vivar, C., Ramirez, M., Morales, M. A., and Lamas, M. (2003). Plasticity of the GABAergic phenotype of the "glutamatergic" granule cells of the rat dentate gyrus. J. Neurosci. 23, 5594-5598.

Hemond, P., Epstein, D., Boley, A., Migliore, M., Ascoli, G. A., and Jaffe, D. B. (2008). Distinct classes of pyramidal cells exhibit mutually exclusive firing patterns in hippocampal area CA3b. Hippocampus 18, 411-24.

Henze, D. A., Urban, N. N., and Barrionuevo, G. (2000). The multifarious hippocampal mossy fiber pathway: a review. Neuroscience $98,407-427$.

Jaffe, D. B., and Gutiérrez, R. (2007). Mossy fiber synaptic transmission: communication from the dentate gyrus to area CA3. Prog. Brain. Res. 163, 109-132.

Jonas, P., Bischofberger, J., and Sandkuhler, J. (1998). Corelease of two fast neurotransmitters at a central synapse. Science 281, 419-424.

Jonas, P., Major, G., and Sakmann, B. (1993). Quantal components of unitary EPSCs at the mossy fibre synapse on CA3 pyramidal cells of rat hippocampus. J. Physiol. 472, 615-663.

Kamiya,H., Shinozaki,H., and Yamamoto, C. (1996). Activation of metabotropic glutamate receptor type $2 / 3$ suppresses transmission at rat hippocampal mossy fibre synapses. J. Physiol. 493, 447-455.

Kannenberg, K., Sieghart, W., and Reuter, H. (1999). Clusters of GABAA receptors on cultured hippocampal cells correlate only partially with functional synapses. Eur. J. Neurosci. 11, 1256-1264.

Kasyanov, A. M., Safiulina, V. F., Voronin, L. L., and Cherubini, E. (2004). GABAmediated giant depolarizing potentials as coincidence detectors for enhancing synaptic efficacy in the developing hippocampus. Proc. Natl. Acad. Sci. U.S.A. 101, 3967-3972.

Kerchner, G. A., and Nicoll, R. A. (2008). Silent synapses and the emergence of a postsynaptic mechanism for LTP. Nat. Rev. Neurosci. 9, 813-825.

Lamas, M., Gomez-Lira, G., and Gutierrez, R. (2001). Vesicular GABA transporter mRNA expression in the dentate gyrus and in mossy fiber synaptosomes. Brain Res. Mol. Brain Res. 93, 209-214.

Lanthorn, T. H., Ganong, A. H., and Cotman, C. W. (1984). 2-Amino-4phosphonobutyrate selectively blocks mossy fiber-CA3 responses in guinea pig but not rat hippocampus. Brain Res. 290, 174-178.

Lauri, S. E., Segerstråle, M., Vesikansa, A., Maingret, F., Mulle, C., Collingridge, G. L., Isaac, J. T., and Taira, T. (2005). Endogenous activation of kainate receptors regulates glutamate release and network activity in the developing hippocampus. J. Neurosci. 25, 4473-4484.

Lauri, S. E., Vesikansa, A., Segerstråle, M., Collingridge, G. L., Isaac, J. T., and Taira, T. (2006). Functional maturation of CA1 synapses involves activity-dependent loss of tonickainate receptor-mediated inhibition of glutamate release. Neuron 50, 415-429.

Lei, S., and McBain, C. J. (2003). GABA B receptor modulation of excitatory and inhibitory synaptic transmission onto rat CA3 hippocampal interneurons. J. Physiol. 546, 439-453.

Leinekugel, X., Khazipov, R., Cannon, R., Hirase, H., Ben-Ari, Y., and Buzsaki, G (2002). Correlated bursts of activity in the neonatal hippocampus in vivo. Science 296, 2049-2052.

Malenka, R. C., and Nicoll, R. A. (1997). Silent synapses speak up. Neuron 19 , 473-476.

Malinow, R., Mainen, Z. F., and Hayashi, Y. (2000). LTP mechanisms: from silence to four-lane traffic. Curr. Opin. Neurobiol. 10, 352-357.

Marchionni,I.,Omrani,A., and Cherubini, E. (2007). In the developing rat hippocampus a tonic $\mathrm{GABA}_{\mathrm{A}}$-mediated conductance selectively enhances the glutamatergic drive of principal cells. J. Physiol. 581, 515-528.

McBain, C. J. (2008). Differential mechanisms of transmission and plasticity at mossy fiber synapses. Prog. Brain Res. $169,225-240$.

Min, M.Y., Rusakov, D. A., and Kullmann, D. M. (1998). Activation of AMPA, kainate, and metabotropic receptors at hippocampal mossy fiber synapses: role of glutamate diffusion. Neuron 21 , 561-570.

Mohajerani, M. H., Sivakumaran, S., Zacchi, P., Aguilera, P., and Cherubini, E. (2007). Correlated network activity enhances synaptic efficacy via BDNF and the ERK pathway at immature CA3-CA1 connections in the hippocampus.Proc. Natl. Acad. Sci.U.S.A. 104, 13176-13181.

Montgomery, J. M., Pavlidis, P., and Madison, D.V. (2001). Pair recordings reveal all-silent synaptic connections and the postsynaptic expression of long-term potentiation. Neuron 29, 691-701.

Nakamura, M., Sekino, Y., and Manabe, T. (2007). GABAergic interneurons facilitate mossy fiber excitability in the developing hippocampus. J. Neurosci. 27, 1365-1373.

Nicoll, R. A., and Schmitz, D. (2005). Synaptic plasticity at hippocampal mossy fibre synapses. Nat. Rev. Neurosci. 6, 863-876.

O'Malley, D. M., and Masland, R. H. (1989). Co-release of acetylcholine and gamma-aminobutyric acid by a retinal neuron. Proc. Natl. Acad. Sci. U.S.A. 86, 3414-3418.

Ottersen, O. P., and Storm-Mathisen, J. (1984). Neurons containing or accumulating transmitter amino acids. In Handbook of Chemical Neuroanatomy, A. Bjorklund, T. Hokfelt and M. J. Kuhar, eds (Amsterdam, Elsevier). pp. 141-246.

Overstreet, L. S., Pasternak, J. F., Colley, P. A., Slater, N. T., and Trommer, B.
L. (1997). Metabotropic glutamate receptor mediated long-term depression in developing hippocampus. Neuropharmacology 36, 831-844.

Rao, A., Cha, E. M., and Craig, A. M. (2000). Mismatched appositions of presynaptic and postsynaptic components in isolated hippocampal neurons. J. Neurosci. 20, 8344-8353.

Ramon y Cajal, S. R. (1911). Histologie du Système Nerveux de l'Homme et des Vertébrés, Vol. II. Maloine, Paris.

Redman, S. (1990). Quantal analysis of synaptic potentials in neurons of the central nervous system. Physiol. Rev. 70, 165-198.

Ritter, L. M., Vazquez, D. M., and MeadorWoodruff, J. H. (2002). Ontogeny of ionotropic glutamate receptor subunit expression in the rat hippocampus. Brain Res. Dev. Brain Res. 139, 227-236.

Romo-Parra, H., Vivar, C., Maqueda, J., Morales, M. A., and Gutierrez, R. (2003). Activity-dependent induction of multitransmitter signaling onto pyramidal cells and interneurons of hippocampal area CA3. J. Neurophysiol. 89, 3155-3167.

Ruiz, A., Fabian-Fine, R., Scott, R., Walker, M. C., Rusakov, D. A., and Kullmann, D. M. (2003). GABAA receptors at hippocampal mossy fibers. Neuron 39, 961-973.

Safiulina, V. F., and Cherubini, E. (2009). At immature mossy fibersCA3 connections, activation of presynaptic $\mathrm{GABA}(\mathrm{B})$ receptors by endogenously released GABA contributes to synapses silencing. Front. Cell. Neurosci. 3, 1-11. doi: 10.3389/neuro.03.001.2009.

Safiulina, V. F., Fattorini, G., Conti, F., and Cherubini, E. (2006). GABAergic signaling at mossy fiber synapses in neonatal rat hippocampus. J. Neurosci. 26, 597-608.

Salin, P. A., Scanziani, M., Malenka, R. C., and Nicoll, R. A. (1996). Distinct short-term plasticity at two excitatory synapses in the hippocampus. Proc. Natl. Acad. Sci. U.S.A. 93, 13304-13309.

Schwarzer, C., and Sperk, G. (1995). Hippocampal granule cells express glutamic acid decarboxylase- 67 after limbic seizures in the rat. Neuroscience 69, 705-709.

Shigemoto, R., Kinoshita, A., Wada, E., Nomura, S., Ohishi, H., Takada, M., Flor, P. J., Neki, A., Abe, T., Nakanishi, S., and Mizuno, N. (1997). Differential presynaptic localization of metabotropic glutamate receptor subtypes in the rat hippocampus. J. Neurosci. 17, 7503-7522.

Sipilä, S. T., Schuchmann, S., Voipio, J., Yamada, J., and Kaila, K. (2006). 
The cation-chloride cotransporter NKCC1 promotes sharp waves in the neonatal rat hippocampus. J. Physiol. 573, 765-773.

Sivakumaran, S., Mohajerani, M. H., and Cherubini, E. (2009). At immature mossy-fiber-CA3 synapses, correlated presynaptic and postsynaptic activity persistently enhances GABA release and network excitability via BDNF and cAMP-dependent PKA. J. Neurosci. 29, 2637-2647.

Sloviter, R. S., Dichter, M. A., Rachinsky, T. L., Dean, E., Goodman, J. H., Sollas, A. L., and Martin, D. L. (1996). Basal expression and induction of glutamate decarboxylase and GABA in excitatory granule cells of the rat and monkey hippocampal dentate gyrus. J. Comp. Neurol. 373, 593-618.

Stirling, R. V., and Bliss, T. V. (1978). Hippocampal mossy fiber development at the ultrastructural level. Prog. Brain Res. 48, 191-198.

Thompson, S. M., Haas, H. L., and Gähwiler, B. H. (1992). Comparison of the actions of adenosine at preand postsynaptic receptors in the rat hippocampus in vitro. J. Physiol. 451, 347-363.

Trigo, F. F., Marty, A., and Stell, B. M. (2008). Axonal GABA receptors. Eur. J. Neurosci. 28:841-848.

Tyzio, R., Holmes, G. L., Ben-Ari, Y., and Khazipov, R. (2007). Timing of the developmental switch in GABA(A) mediated signaling from excitation to inhibition in CA3 rat hippocampus using gramicidin perforated patch and extracellular recordings. Epilepsia 48, 96-105.

Uchigashima, M., Fukaya, M., Watanabe, M., and Kamiya, H. (2007). Evidence against GABA release from glutamatergic mossy fiber terminals in the developing hippocampus. J. Neurosci. 27, 8088-8100.

Urban, N. N., Henze, D. A. and Barrionuevo, G. (2001). Revisiting the role of the hippocampal mossy fiber synapse. Hippocampus 11, 408-417.
Vignes, M., and Collingridge, G. L. (1997). The synaptic activation of kainate receptors. Nature 388, 179-182.

Vogt, K. E., and Nicoll, R. A. (1999). Glutamate and gamma-aminobutyric acid mediate a heterosynaptic depression at mossy fiber synapses in the hippocampus. Proc. Natl. Acad. Sci. U.S.A. 96, 1118-1122.

Voronin, L. L., and Cherubini, E. (2004). 'Deaf, mute and whispering' silent synapses: their role in synaptic plasticity. J. Physiol. 557, 3-12.

Walker, M. C., Ruiz, A., and Kullmann, D. M. (2001). Monosynaptic GABAergic signaling from dentate to CA3 with a pharmacological and physiological profile typical of mossy fiber synapses. Neuron 29, 703-715.

Weisskopf, M. G., Zalutsky, R. A., and Nicoll, R.A. (1993). The opioid peptide dynorphin mediates heterosynaptic depression of hippocampal mossy fibre synapses and modulates long-term potentiation. Nature 362, 423-427.
Conflict of Interest Statement: The authors declare that the research was conducted in the absence of any commercial or financial relationships that could be construed as a potential conflict of interest.

Received: 05 January 2010; paper pending published: 25 January 2010; accepted: 02 February 2010; published online: 22 February 2010.

Citation: Safiulina VF, Caiati MD, Sivakumaran S, Bisson G, Migliore $M$ and Cherubini E (2010) Control of $G A B A$ release at single mossy fiber-CA3 connections in the developing hippocampus. Front. Syn. Neurosci. 2:1. doi: 10.3389/neuro.19.001.2010

Copyright (c) 2010 Safiulina, Caiati, Sivakumaran, Bisson, Migliore and Cherubini. This is an open-access article subject to an exclusive license agreement between the authors and the Frontiers Research Foundation, which permits unrestricted use, distribution, and reproduction in any medium, provided the original authors and source are credited. 